\title{
VALUE OF A SYSTEMIC INSECT GROWTH REGULATOR, LUFENURON, ADMINISTERED ORALIY IN THE CONTROL OF CTENOCEPHALIDES FELIS
}

\author{
FRANC M.* \& CADIERGUES M.-C.*
}

\section{Summary :}

Twenty five dogs of various breeds, weighing between 2.5 and $34 \mathrm{~kg}$, were used in two trials carried out during the summer of 1991 and spring of 1992 respectively. In both trials,

50 Ctenocephalides felis were placed weekly on each dog over a period of four weeks. The development of the flea populations in the treated animals was compared with that in untreated controls. The oral administration of Lufenuron (Program $($ ) ) before each infestation in dosages of at least $10 \mathrm{mg} / \mathrm{kg}$ every four weeks provided complete control of the flea populations. Fleas had almost completely disappeared two to three weeks after the last infestation. Under the same conditions, the control animals harboured on average 80 fleas at the end of the trial in the summer, and 40 fleas in the spring.

The results provided information on the fate of fleas following initial experimental infestation. Five days after the first infestation, only $27 \%$ of the 1,300 fleas deposited survived and escaped grooming. The results also showed that in treated animals, in the absence of re-infestation, the 800 fleas deposited on the 28th day did not persist for more than two to three weeks in the dogs' coats.

KEY WORDS : Ctenocephalides felis, biology, control, Lufenuron, dog. MOTS CLÉS : Ctenocephalides felis, biologie, contrôle, Lufénuron, chien.

\section{INTRODUCTION}

1 he cat flea Ctenocephalides felis felis is the most common flea of dogs and cats in France. This pest is often difficult and expensive to control on pets and in households. All new products are popular immediately after launch indicating that owners are unhappy, or not completely satisfied, with the efficacy of previous formulations. This poor efficacy is not solely due to the product, but is frequently due to poor choice or incorrect use associated with a lack of understanding of the biology of the parasite (Franc, 1994).

Amongst the new means of control, the use of chitin synthesis inhibitors (IGR) appears to be of interest in

\footnotetext{
* Unité de Dermatologie-Parasitologie, École Nationale Vétérinaire de Toulouse, 23, chemin des Capelles, F-31076 Toulouse Cedex, France.
}

Tél: (33) 05611938 73. Fax: (33) 0561193971.
Résumé : INTÉRÊT D'Un RÉGULATEUR DE CROISSANCE DES INSECTES SYSTÉMIQUE : LE LUfÉNURON, DANS LA LUTTE CONTRE CTENOCEPHALIDES FELIS Vingt-cing chiens de races diverses pesant entre 2,5 et $34 \mathrm{~kg}$ ont été utilisés dans deux essais menés respectivement pendant l'été 1991 et le printemps 1992. Dans les deux essais, 50 Ctenocephalides felis ont été déposées chaque semaine, une fois par semaine sur chaque chien soit au total 250 puces. Le développement des populations de puces chez les animaux témoins a été comparé à celui obtenu chez les animaux traités. L'administration de Lufénuron (Program@) par voie orale, avant les infestations, à la posologie d'au moins $10 \mathrm{mg} / \mathrm{kg}$ toutes les quatre semaines a entraîné un contrôle complet des populations de puces : elles ont disparu deux à trois semaines après la dernière infestation. Dans les mêmes conditions en fin d'essai, le lot témoin hébergeait 80 puces pour l'essai déroulé en été et 40 pour celui du printemps.

Ces essais nous permettent aussi une meilleure connaissance du devenir des puces après une infestation expérimentale : cinq jours après la primo-infestation, seulement $27 \%$ des 1300 puces déposées ont survécu et échappé à l'ingestion par le chien. Les essais montrent également que chez les animaux traités, en l'absence de réinfestation, les 800 puces déposées le 28e jour n'ont pas persisté plus de deux à trois semaines dans le pelage des animaux. the control of flea populations. Administered via the oral route, Lufenuron (Hink, Zakson and Barnett, 1994; Zakson, Hink and Mac Kichan, 1992) is absorbed by adult fleas during their meal of blood. The adult female flea does not die, but its eggs cannot hatch, or, if there are larvae, they are unable to develop normally. The advantage of the systemic mode of action of this molecule lies in the fact that it interrupts the life cycle of the flea, thereby limiting re-infestation. The value of this compound was demonstrated during a controlled trial on dogs infested experimentally with Ctenocephalides felis.

\section{MATERIALS AND METHODS}

Housing AND HANDLING OF DOGS

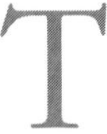
wenty five dogs of various breeds and weighing between 2.5 and $34 \mathrm{~kg}$ were used in two trials carried out during the summer of 1991 and spring of 1992 respectively. 
For each trial, dogs were allocated into three groups according to weight (table I). Two groups were treated with Lufenuron, and the third received no treatment (negative control).

Each group of dogs was placed in a different room each measuring $3.4 \mathrm{~m}$ by $3.4 \mathrm{~m}$. The walls were smooth rough-cast, and the premises were steam disinfected before the beginning of each trial. There was a straw-covered area in each room. The straw was not changed, and the area was used by the dogs to lie on, and for the fleas to reproduce. The concrete floor of the remaining area was cleaned daily. The dogs received a commercial dry food daily and had access to water ad libitum. The distribution of the animals in the two trials is shown in table I.

FLeAS

The flea strain C. felis felis was isolated from a cat five years ago and maintained in our laboratory on cats. C. felis felis is the main strain (more than $99 \%$ ) isolated from dogs at the ENVT consultations. The young fleas between 1 and 3-days-old were placed in a glass crystallizing dish and 50 were aspirated into plastic bottles, which were then used to infest the dogs by depositing them along the dorso-lumbar line.

\begin{tabular}{|c|c|c|c|c|}
\hline Group Nb & Dogs Nb & Weight & $\begin{array}{l}\text { Treatment } \\
\text { per dog }\end{array}$ & $\begin{array}{l}\text { Dose received } \\
(\text { min-max) }\end{array}$ \\
\hline \multicolumn{5}{|c|}{ Trial of summer 1991 (2 juil. 91-1 ${ }^{\text {er }}$ oct. 91) } \\
\hline 1 & 3 & 2.5 to $5 \mathrm{~kg}$ & $1 \times 68 \mathrm{mg}$ & 13.6 to $27.2 \mathrm{mg} / \mathrm{kg}$ \\
\hline 2 & 5 & 9.6 to $12.2 \mathrm{~kg}$ & $1 \times 204.6 \mathrm{mg}$ & 16.7 to $21.3 \mathrm{mg} / \mathrm{kg}$ \\
\hline 3 & 5 & 10 to $13.2 \mathrm{~kg}$ & 0 & 0 \\
\hline \multicolumn{5}{|c|}{ Trial of spring 1991 (17 mars $92-16$ juin 92 ) } \\
\hline 4 & 4 & 23 to $34 \mathrm{~kg}$ & $1 \times 409.8 \mathrm{mg}$ & 12.1 to $17.8 \mathrm{mg} / \mathrm{kg}$ \\
\hline 5 & 4 & 23 to $28 \mathrm{~kg}$ & $2 \times 204.9 \mathrm{mg}$ & 12.1 to $14.6 \mathrm{mg} / \mathrm{kg}$ \\
\hline 6 & 4 & 22 to $27 \mathrm{~kg}$ & 0 & 0 \\
\hline
\end{tabular}

Table I. - Distribution of the animals.

\begin{tabular}{|c|c|c|c|c|}
\hline & & $\begin{array}{c}\text { Group } 1 \\
68 \mathrm{mg}\end{array}$ & $\begin{array}{l}\text { Group } 2 \\
204.9 \mathrm{mg}\end{array}$ & $\begin{array}{c}\text { Group } 3 \\
\text { control }\end{array}$ \\
\hline $\mathrm{D}-1$ & & 0 & 0 & 0 \\
\hline Do & TR. & 0 & 0 & 0 \\
\hline$D+2$ & INF. & 0 & 0 & 0 \\
\hline$D+7$ & INF. & $17.3 \pm 19.7$ & $12 \pm 4.7$ & $19.4 \pm 12.1$ \\
\hline$D+14$ & INF. & $29.0 \pm 29.7$ & $14.8 \pm 6.6$ & $26 \pm 19.2$ \\
\hline$D+21$ & INF. & $18.5 \pm 23.3$ & $9 \pm 6.9^{*}$ & $32 \pm 23.9$ \\
\hline $\mathrm{D}+28$ & INF. TR. & $28.5 \pm 36.1$ & $12.2 \pm 7.8^{*}$ & $43 \pm 25.9$ \\
\hline$D+35$ & & $26.0 \pm 33.9$ & $16.8 \pm 4.4^{*}$ & $56 \pm 28.8$ \\
\hline$D+42$ & & $4.5 \pm 6.4^{*}$ & $2.2 \pm 0.8^{*}$ & $65 \pm 21.8$ \\
\hline$D+49$ & & $1.0 \pm 1.4^{*}$ & $0.2 \pm 0.4^{*}$ & $68 \pm 20.8$ \\
\hline$D+56$ & TR. & $0.5 \pm 0.7^{*}$ & $0^{*}$ & $71 \pm 26.3$ \\
\hline$D+63$ & & $1.0 \pm 1.4^{*}$ & $0^{*}$ & $72 \pm 18.2$ \\
\hline$D+70$ & & $0.5 \pm 0.7^{*}$ & $0.2 \pm 0.4^{*}$ & $70 \pm 21.2$ \\
\hline$D+77$ & & $1.0 \pm 1.4^{*}$ & $0^{*}$ & $74 \pm 22.7$ \\
\hline$D+84$ & TR. & $2.5 \pm 2.1^{*}$ & $0.2 \pm 0.4^{*}$ & $76 \pm 19.5$ \\
\hline$D+91$ & & $2.5 \pm 0.7^{*}$ & $0^{*}$ & $83 \pm 39.3$ \\
\hline
\end{tabular}

INF : Infestation with 50 adult fleas.

TR : Treatment with Lufenuron.

* Significant difference between treated group and control for $p<0.05$.

Table II. - Trial in summer 1991: mean flea count ( \pm standard deviation). 


\begin{tabular}{|c|c|c|c|c|c|}
\hline & & & $\begin{array}{c}\text { Group } 4 \\
409.8 \mathrm{mg}\end{array}$ & $\begin{array}{c}\text { Group } 5 \\
2 \times 204.9 \mathrm{mg}\end{array}$ & $\begin{array}{l}\text { Group } 6 \\
\text { control }\end{array}$ \\
\hline$D-1$ & & & 0 & 0 & 0 \\
\hline D0 & & TR. & 0 & 0 & 0 \\
\hline$D+2$ & INF. & & 0 & 0 & 0 \\
\hline$D+7$ & INF. & & $11.25 \pm 3.3$ & $13.25 \pm 2.75$ & $11.75 \pm 2.87$ \\
\hline$D+14$ & INF. & & $18.75 \pm 4.79$ & $21.75 \pm 3.95$ & $21.75 \pm 7.89$ \\
\hline $\mathrm{D}+21$ & INF. & & $21.75 \pm 7.68$ & $25 \pm 7.07$ & $26.25 \pm 10.31$ \\
\hline $\mathrm{D}+28$ & INF. & TR. & $27.5 \pm 8.66$ & $29.25 \pm 7.23$ & $30.5 \pm 13.2$ \\
\hline$D+35$ & & & $15 \pm 7.07$ & $22.5 \pm 11.9$ & $35 \pm 10.8$ \\
\hline$D+42$ & & & $0^{*}$ & $0^{*}$ & $23.75 \pm 13.77$ \\
\hline$D+49$ & & & $0^{*}$ & $0^{*}$ & $28.75 \pm 13.77$ \\
\hline$D+56$ & & TR. & $0^{*}$ & $0.25 \pm 0.5^{*}$ & $32.5 \pm 15$ \\
\hline$D+63$ & & & $0^{*}$ & $0^{*}$ & $35 \pm 12.25$ \\
\hline$D+70$ & & & $0^{*}$ & $0^{*}$ & $33 \pm 12.36$ \\
\hline$D+77$ & & & $0^{*}$ & $0^{*}$ & $35 \pm 12.25$ \\
\hline$D+84$ & & TR. & $0^{*}$ & $0^{*}$ & $36.25 \pm 13.77$ \\
\hline$D+91$ & & & $0^{*}$ & $0^{*}$ & $40.5 \pm 14.98$ \\
\hline
\end{tabular}

INF : Infestation with 50 adult fleas.

TR: Treatment with Lufenuron.

* Significant difference between treated group and control for $p<0.05$.

Table III. — Trial in spring 1992: mean flea count ( \pm standard deviation).

\section{COUNTING THE FLEAS}

The fleas were counted by detailed visual examination of each animal by brushing the coat the wrong way. A comb was not used to avoid trauma to the fleas. Preliminary trials showed that for light or moderate infestations there was little or no difference between the number of fleas counted visually in the coat, and the number obtained after counting the fleas collected after combing.

\section{Clinical eXamination of THE animals}

The animals were checked up twice a day for six days a week throughout the trial. At each flea count, all the animals were weighed and subjected to a full clinical examination including measurement of rectal temperature, a skin examination noting any lesions, and an assessment of pruritus.

THE COMPOUND

Lufenuron (1-(2.5-dichloro-4-(1.1,2,3,3,3, hexafluoropropoxy)phenyl)-3-(2.6-difluorobenzoyl) urea; CGA184699), a chitin synthesis inhibitor was developed by Ciba Geigy. Lufenuron tablets (Program ${ }^{\circledR}$ Ciba $\mathrm{SA}^{1}$ ) are available in three formulations for dogs: 68, 204.9 or $409.8 \mathrm{mg}$.

1. Ciba SA, 8, rue Lionel Terray, F-92506 Rueil-Malmaison.

\section{TRIAL PROCEDURE}

The dogs were previously cleared of all ectoparasites by successive combings. They then received the treatment allocated at random (table I), and were placed in their respective rooms where they remained until the end of the trial. On the 2nd, 7th, 14th, 21st and 28 th days after treatment they were individually infested with 50 inbred 3-day-old adult C. felis.

The flea populations were counted before treatment, on $\mathrm{D}+2, \mathrm{D}+7$, then once a week until the end of each trial. Lufenuron was administered via the oral route on D0 and repeated in the same way every four weeks. The individual doses ranged from 12.1 to $27.2 \mathrm{mg} / \mathrm{kg}$.

\section{STATISTICS}

Data were expressed as means \pm SD. The treated groups were compared to the control group using Student's t-test. Differences were considered significant for $p<0.05$.

\section{RESULTS}

\section{TOLERANCE}

T $\mathrm{n}$ agreement with the results of other authors (Lynn et Campbell, 1992), the formulation was well tolerated by all the animals.

\section{EFFECTIVENESS ON FLEA POPULATIONS}

The results of the flea counts are given in tables II and III with the means and standard deviations for each 
group of dogs. The results were also presented graphically along with the average weekly outside temperature as well as the maximum and minimum recorded over the week. The extreme outside relative humidities for the week are also shown (Figs 1 and 2).

The three counts carried out at the start of each trial confirmed that all the animals were free of fleas at the time of experimentation.

During the summer of 1991, flea populations increased regularly in the controls due to successive infestations and the rapid proliferation of the fleas. The life cycle of the cat flea was completed more rapidly in warm weather. The mean number of fleas in the controls reached 43 fleas per $\operatorname{dog}( \pm 25.9)$ in the fourth week and $83( \pm 39.3)$ at the end of the trial (week 13).

The mean number of fleas increased more slowly in the controls at the lower temperatures of spring 1992. The populations were observed to increase due to reproduction after the seventh week.

In the treated animals, the repeated experimental infestations led to mean flea populations ranging from nine to 28 in the weeks following each infestation for the trial carried out in summer 1991, and from 11 to 29 for the trial carried out in spring 1992.
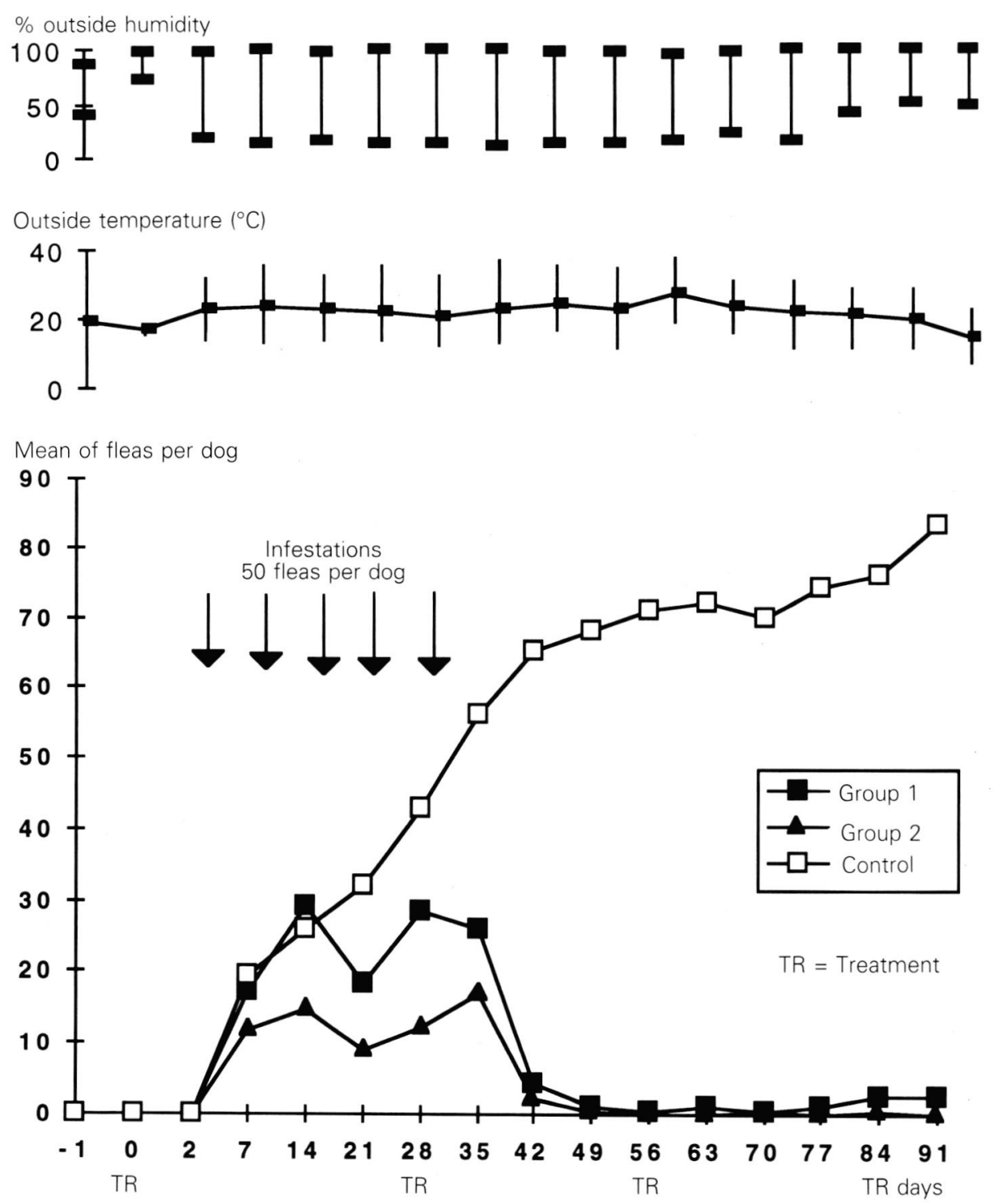

Fig. 1. - Trial in summer 1991. 

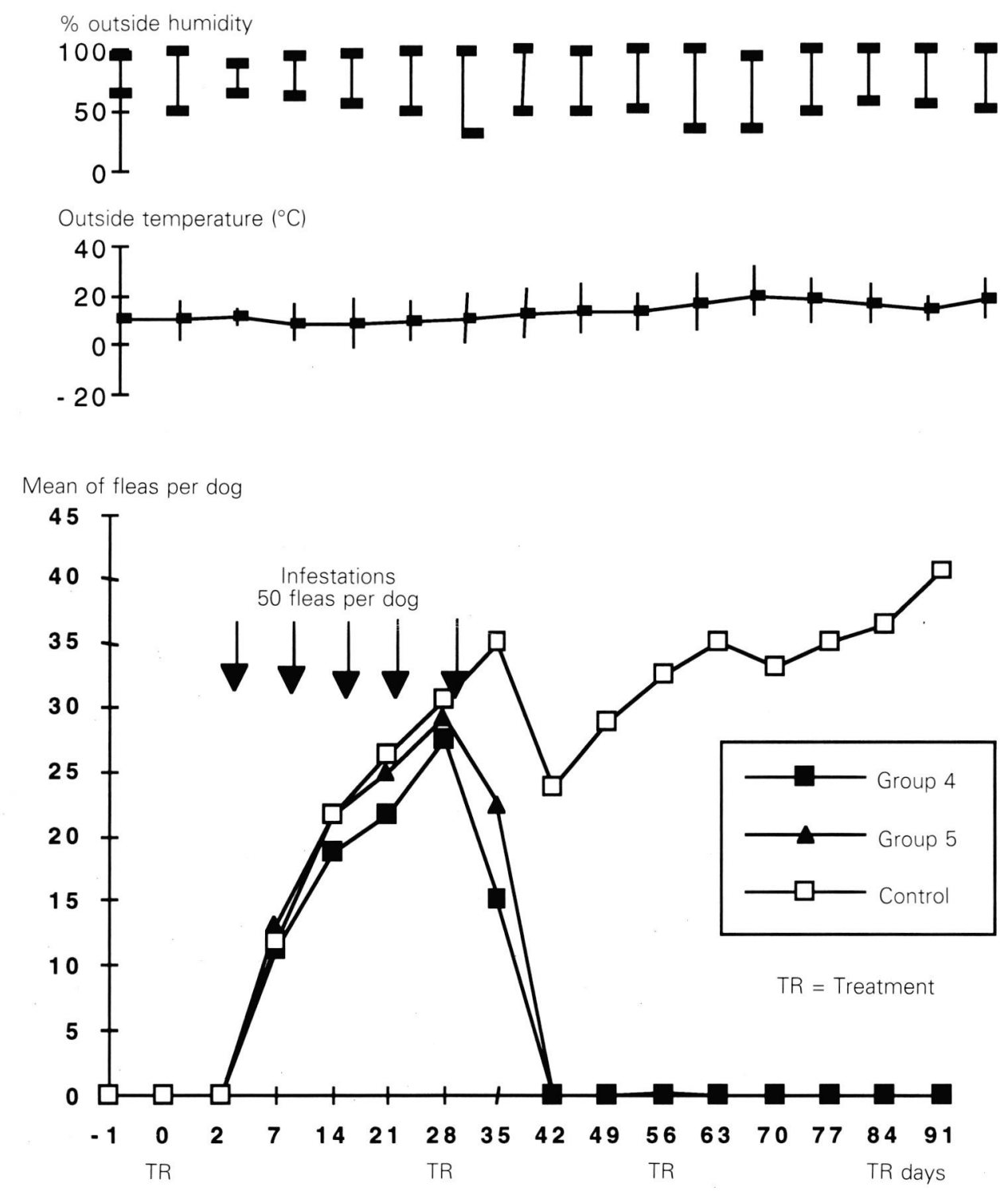

Fig. 2. - Trial of spring 1992.

One week after the last experimental infestation on D28, a large number of fleas was recorded: 26, 17, 15 and 23 for groups 1,2, 4 and 5 respectively, due to the survival and persistence in the coat of the parasites deposited on previous infestations.

The populations of $C$. felis decreased sharply to near zero from the 42nd day for the 1992 trial, and from the 49th day for the 1991 trial. Thereafter, populations remained very low or absent (spring trial).

There were statistically significant differences from the 42nd day for all the treated groups (Groups 1, 2, 4, 5 versus control, $\mathrm{p}<0.05$ ). In group 2 , the difference (versus control, $\mathrm{p}<0.05$ ) was significant by $\mathrm{D} 21$.

\section{SKIN SYMPTOMS}

The presence of fleas in large numbers caused pruritus in all the animals at the beginning of the trial, together with hair loss on the dorso-lumbar region; this was more apparent in the animals from groups 1 and 3 as the trial was carried out in summer, and the higher temperature in the unit $\left(>20^{\circ} \mathrm{C}\right)$ favored proliferation of the fleas.

These signs were exacerbated in the control animals, particularly those in group 3, whereas they declined during the month following disappearance of the fleas in the dogs in group 4 that received Lufenuron. 


\section{DISCUSSION}

T hese two trials, carried out under the same experimental conditions but in different seasons, evaluated the effectiveness of treatment with Lufenuron, and provided further understanding of the biology of C. felis, i. e. its persistence in the coats of the animals.

Lufenuron at the dosages between $12.1 \mathrm{mg} / \mathrm{kg}$ and $27.2 \mathrm{mg} / \mathrm{kg}$ every four weeks, effectively controlled infestation of dogs by C. felis. Two to three weeks after the last infestation, flea populations were very low or even absent, and remained so until the end of each trial.

The 250 fleas deposited on each treated animal were therefore unable to reproduce, whereas in the controls the populations increased. This demonstrates that, at this dosage, Lufenuron persists for at least 28 days at levels that prevent reproduction of the female fleas feeding on the treated animals.

Five days after the first infestation, on average only $27 \%$ of the 1,300 fleas deposited on the 25 dogs had survived and escaped grooming.

The 800 fleas deposited on the 28th day of the trial on the treated animals did not survive for more than two to three weeks. As Lufenuron has no effect on the viability of the adults (Hink, Dought and Barnett, 1991), the life-span of the fleas was assumed to be no longer than two to three weeks, although other authors have reported that fleas live for between 11 days and two years (Dryden, 1989).

\section{CONCLUSION}

he chitin synthesis inhibitor Lufenuron, administered orally to the infected $\operatorname{dog}$ in a minimum dosage of $10 \mathrm{mg} / \mathrm{kg}$, prevented the development of the offspring of adult female fleas feeding on the animal. In our trials, the animals received dosages ranging from 12.1 to $27.2 \mathrm{mg} / \mathrm{kg}$ administered in commercial formulations. In all cases treatment was extremely effective, as no parasites were found two to three weeks after the last infestation. In the absence of re-infestation, fleas survived for only two to three weeks in the animals' coats.

\section{REFERENCES}

Dryden M.W. Host association, on-host longevity and egg production of Ctenocephalides felis felis. Veterinary Parasitology, 1989, 34, 117-122.

Franc M. Fleas and control methods. Revue Scientifique de l'Office International des Epizooties, 1994, 13, 1019-1037.

Hink W.F., Dought D.C. \& BarnetT S. Effect of an experimental systemic compound, CGA-184699, on life stages of the cat flea (Siphonaptera : Pulicidæ). Journal of Medical Entomology, 1991, 28, 424-427.

Hink W.F., Zakson M. \& BarnetT S. Evaluation of a single oral dose of Lufenuron to control flea infestations in dogs. American Journal of Veterinary Research, 1994, 55, 822824.

Lynn R.C. \& CAmpbell W.R. Tolerability of Lufenuron (CGA184699) in normal dogs and cats. Proceedings of the 10th American College of Veterinary Internal Medicine forum, May 29, 1992, San Diego, California.

Zakson M. \& Hink W.F. Fate of the Benzoylphenyl urea CGA184699 in the cat flea Ctenocephalides felis. Pesticide Science, 1992, 35, 117-123.

Reçu le 2 janvier 1996 Accepté le 21 avril 1996

\section{ACKNOWLEDGEMENTS}

We are grateful for the support of Jean Steffan from Ciba SA. 